ISSN 1112-9867

\title{
USING WIND TURBINES IN SKY SCRAPERS TO DEVELOP THESTABLE ARCHITECTURE (CASE STUDY: KISH ISLAND)
}

\author{
M. H. R. Fard ${ }^{1}$, S. Khastu ${ }^{1}$, F. Asadpur ${ }^{2, *}$ \\ ${ }^{1}$ Department of architectural, Mahmudabad branch, Islamic Azad University Mahmudabad, \\ Iran \\ ${ }^{2}$ Architecture engineering M.S student, the Sama technical institution teacher, nourbranch, \\ Islamic Azad University nour, Iran
}

Published online: 18 June 2016

\begin{abstract}
The daily increasing and irregular consumption of fossil fuels as the limited energy source and its destructive effect on the environment has attracted all people attention to use the renewable energies and in this extend, application of renewable energies like wind is one of the frequent options in all around the world in order to produce pure and low cost energy, but due to population concentration and economical activities in the recent cities and as the result the sky scrapers building number increase to respond this problems has caused irreparable effects in the environment, therefore to protect the natural sources, reduction of environmental pollution and reduction of energy consumption, supplying the wind turbine has play the important role to produce wind energy and changing it to mechanical energy and also electricity to fulfill the stable development in the building section, so because in the shallow areas in the Persian gulf and beaches in the region are the proper locations for installation of wind turbine, in this article by studying documents and field evaluation we have attempted to evaluate the wind energy application in the sky scrapers buildings structures in this region to save and optimize the energy consumption without any environmental destructive effect that such issue has led to better programming to sky scrapers structures construction in Kish Island to achieve the stable development purposes.
\end{abstract}

Keywords: renewable energy, wind energy, wind turbine, high buildings, Kish Island, stable architecture

Author Correspondence, e-mail: asadpoor.faezeh@yahoo.com

doi: http://dx.doi.org/10.4314/jfas.v8i2s.154 


\section{INTRODUCTION}

The strategy to develop the space construction in high stature as the population product and increase of urbanization and also lack of proper land for construction has progressed in recently decades. The formation of this type of buildings according to the specifications and its features naturally beside its positive effect also has faced with limitations and threats, Golabchi in 2001. The most important issue in these types of buildings is attention to applicants concentration in their limit area, application and using high energy during construction at the time of operation is also significant, so it is essential that in designing sky scrapers buildings the strategies are taken in to consideration to face this problem in order to save energy especially about the none-renewable energies by the purpose of its protection for the future generation that is the main target of stable development, Daneshpur et al in 2009. In this direction using the renewable energies in order to produce electricity is inevitable. In this extend due to low cost of electricity production by wind power compared to other renewable sources, electricity production by the wind power has been taken in to attention greatly, Howington in 1987. While if adequate wind blows during the year in a city, wind is the proper option to produce electricity in the house, Hajian in 2015, so in the world the beaches are the best regions to install the wind turbines. In these regions the wind speed compared to land has higher rate because the wind fraction with water compared to landis in lower degree, Gandomkar in 2000. In this extend the shallow water in Persian Gulf and Thisregion Island are the proper lands to install the wind turbine, in region which there is the stable winding with speed of more than 8 nuts (four mete per second) we can use the wind turbine for various application, Badrtan in 2003

In wind condition evaluation in the synoptic station during 1981 to 1985 , it was identified that generally at the whole country the Zabul station at Sistan region has the best condition to install the wind turbine field, Kaviany in 2005, after the Sistanregion, Persian gulf beaches have proper condition to install the wind turbine, Gandomkar in 2006 and because the Kish island is located at the south of Iran and in the Persian gulf beach beside the Hurmozgan province and based on the statistics the wind blowing in 3 hours in Kish island station, the wind speed annual average in this island in 8.6 nuts (4.3 meter per second) and the maximum speed of wind that is registered in station no.47 is 23.5 meter per second that it is more than the intended average and it has made the wind turbine construction possible in these regions, Gandomkar in 2010. 
So in this research by evaluation of wind energy application in the sky scrapers structures at the Persian gulf beaches to save energy and optimize consumption of energy without the destructive effect, it has been attempted to parallel application of this energy as a priority in Kish region construction to have stable development by the purpose if energy consumption optimization and minimizing the environmental pollution.

\section{Sustainability concept}

\section{Stability in the terminology}

The verb sustain was applied in English language since 1290 and is derived from the Latin root sub and ten ere that means holding or protecting. The meaning and other formation of this term existed during many years so in recent decades the term stability with its present meaning that is referred to what could exist for future, has found application, Dehqhany in 2013.

In the Persian culture and dialect stability means to be stable and resistance from the root resistant to show persistence, for the term stability these definitions are prepared, having stability and continuity and persistent, so the term stability that is used equally to sustainability lacks of modern meaning and emphasizes of the protection and starlit, the term stability which is discussed in this article includes what could be remained for future, Asadpur in 2003.

\section{Stable development}

Following to the stable society, other concepts as the development protection are formed to guarantee the people life and welfare, although in this time development could be a threat if sources did not protected properly, evaluations led to announcement of report by title of common future in 1987. Simultaneously by the end of cold war and discovery of ozone layer hole in 1985 and one year after the Chernobyl event, this report emphasized on a main axis that most of present development procedures has made many people poorer and more vulnerable and cause damages to environment, so how this development could be effective in future with double population, so we need one path of development that leads to progress and breakthrough for human not only in some location and for some year rather for the whole planet and for far future and therefore the most acceptable development issue emerged. The stable development is the development that provides the present world requirements without putting the future generation in danger in obviating his needs, Qhobadian in 2003.

\section{Stable architecture}


The stability concept application and stable development in the architecture has made a discussion and the stable architecture. The stable architecture main ideas included the application variation capability and hidden energy that is used for the material and elements productions, Soleimany in 2008 considered the stable architecture as other architectural issues which have the special principals and regulations and it includes three phases, energy saving in sources and designing to return to the life circle, designing for human that each of them has its special strategy and studying these strategies will provide more realization of environment for designing, Davodi Nejad in 2009.

\section{Stable designing principals}

Some of structures have specifications and features that categorize them in stable structures, the principals that must be obeyed to categorize architecture as stable are including as below: First role: energy saving, the structure should be designed that minimizes the building requirements to the fossil fuels

Second role; the climate conformity: the structures should be designed as they keep conformity with the climate and energy sources in the establishment location

Third role: reduction of material new source application: buildings should be designed as the new source usage is minimized as much as possible and at the end of their beneficial life, they are used for the new source for building a new structure

Fourth principal: inhabitant requirements provision: in the stable architecture providing the mental and physical needs to inhabitants has special importance

Fifth role; coordination with site; the building should be located in the site land properly and it should have conformity with the environment

Sixth role; the totally, all stable architectural roles should be considered in a completed process that leads to construction of safe environment, Asadpur in 2013.

\section{Stable view in high buildings}

Building high structures in the world is the phenomenon that is registered in the late $19^{\text {th }}$ century and at the beginning of $20^{\text {th }}$ century and the first steps in making towers started from 1880 to 1900 , Azizy in 1998 . In the $20^{\text {th }}$ century issues as the population increasing and need for more people inhabitance in cities and the necessity to use land in the cities crowded centers and also the need to reconstruct in the civil regions, the people need for living or working in city centers and the necessity to reduce the costs due to cities horizontal expansion are considered as factors that has made the high buildings construction as need in the world mega cities, Golabchi in 2001. Because usually these structures consume high rate 
of energy and sources during construction and even when they come to the end of their life and they are destroyed, they also have high energy lost, so typically they are in contrast with the stability purposes. But according to the necessities that are frequent in the present time for the high stature construction, it is necessary that designers and respo0nsible agents try to reduce the negative effects on the environment and also impacts on the applicants from other hand, hence this research is done by the purpose if stability fulfillment in the high stature buildings.

\section{Wind turbines and wind renewable energy}

The wind turbine as other renewable energies is expanded geographically and it is not concentrated and almost it is always assessable. Of the wind energy application benefits we can point out to below issues

- Lack of necessity to fuel in wind turbines that as the result the fossil fuel consumption rate is reduced

- Free cost of wind energy

- Capability to provide a part of electricity energy requirement

- Low cost of obtained energy from wind compared to other fossil energies

- Low cost of current expends in investment for wind energy in long run

- Variety of energy sources and making stable energy

- Lack of any need to water

- Lack of environmental pollution compared to fossil fuels, Iran new energies organization informing office

Wind turbines is composed of a tower that a motor chamber is located at the top in which the generator or more scientifically the gearbox, main axel and other electrical equipments are located in it, by blowing wind and contact of air layers to the turbine blades that are connected to main axel, blades start to turn around and transfer rotating energy to main axel but because the wind speed to turn the main axel in not enough to run in high rotations, a gearbox is used and the low speed of turbine blades is changed to high speed, the rate of this speed is depended to the generator type and in many cases, it is 50 times more than the turbine blade rotation, Khalaji Asad and Safay in 2001.

The process of performance in a turbine is actually at the fan reverse operation. In the electrical fan the electricity is changed to mechanical energy and causes the rotation in fan but in the turbines the wind kinetic energy is changed to mechanical energy and then it is changed to electricity, wind contacts to the blades and rotates them and the blades 
rotation leads to the main axel rotation and this axel is connected to generator and generator rotation produces the alternative electricity, Iran new energy organization informing center, Sana.

\section{Wind energy potential in Iran}

The wind energy potential studying to produce electricity and other application is one of the most important issues in using wind energy. Most of countries around the world have proceeded to apply the wind energy to provide the wind energy potential designs; above studies have lower difficulty in plain areas and in the mountain regions which are not faced with the atmosphere general flows. The local winds studying has more importance, we can consider Iran as second categorization according to the topographical condition and geographical limitation and also the expansion on this country that includes the beach and local winds. In this relation we can name to the Iran north regions as Manjil, Rodbal and north of Qhazvin. Based on the operated measurements the produced energy in these regions is between 900 to 1500 watts in each square meter. The Persian Gulf regions and beaches have proper condition to install the wind turbine, Mostafaie in 2015. In these regions the wind speed is high than other lands because the air fraction with water is lower than air fraction with land, Gandomkar in 2010 because in the regions where the frequent wind blows with 8 nuts ( 4 meter per second) it is possible to use the wind turbines for various application, badrran in 2003.

\section{Wind blowing statistical evaluation in KishIsland}

The Kish Island is located at the south of Iran in the Persian Gulf beside the Hurmozgan province. Based on the 3 hours statistics evaluation in the Kish island station the average wind speed annually in 8.6 nuts (4.3 meter per second) and the maximum wind speed in this station is 47 nuts (23.4 meter per second), Gandomkar in 2010. In $45.7 \%$ of registered times, the wind speed was at zero or lower than 8 nuts but it is not suitable to use the wind energy and in $54.3 \%$ of time the wind speed is more than 8 nuts and it was proper for the wind energy application to run turbines. In $40.2 \%$ of time the wind speed is between 8 to 16 nuts and in $13 \%$ of times it is between 16 to 24 nuts and in 15 it was more than 24 nuts, figure1, Gandomkar in 2010.

The wind blowing direction with speed of more than 8 nuts in this station has a main direction and a subsidiary direction that is against the wind blowing and about $47 \%$ of blowing were between 270 to 310 degrees and in $18 \%$ of cases the blowing were between 90 to 120 degrees, actually we can say that the fastest winds in Kish island have a main 
direction to west and a subsidiary direction to east, figure 2,3 that in most of times during year the wind blowing direction is stable in the Kish island station. According to the wind blowing with high speed and stable direction during a year and also presence of shallow beaches beside this island we can establish the wind field in the beaches water around the Kish island and use the wind energy to produce the require electricity for this island during most of year intervals and it assists greatly to the Kish island environment protection and totally the Persian gulf and stable development in this region, 2010.

$\mathrm{KISH}$

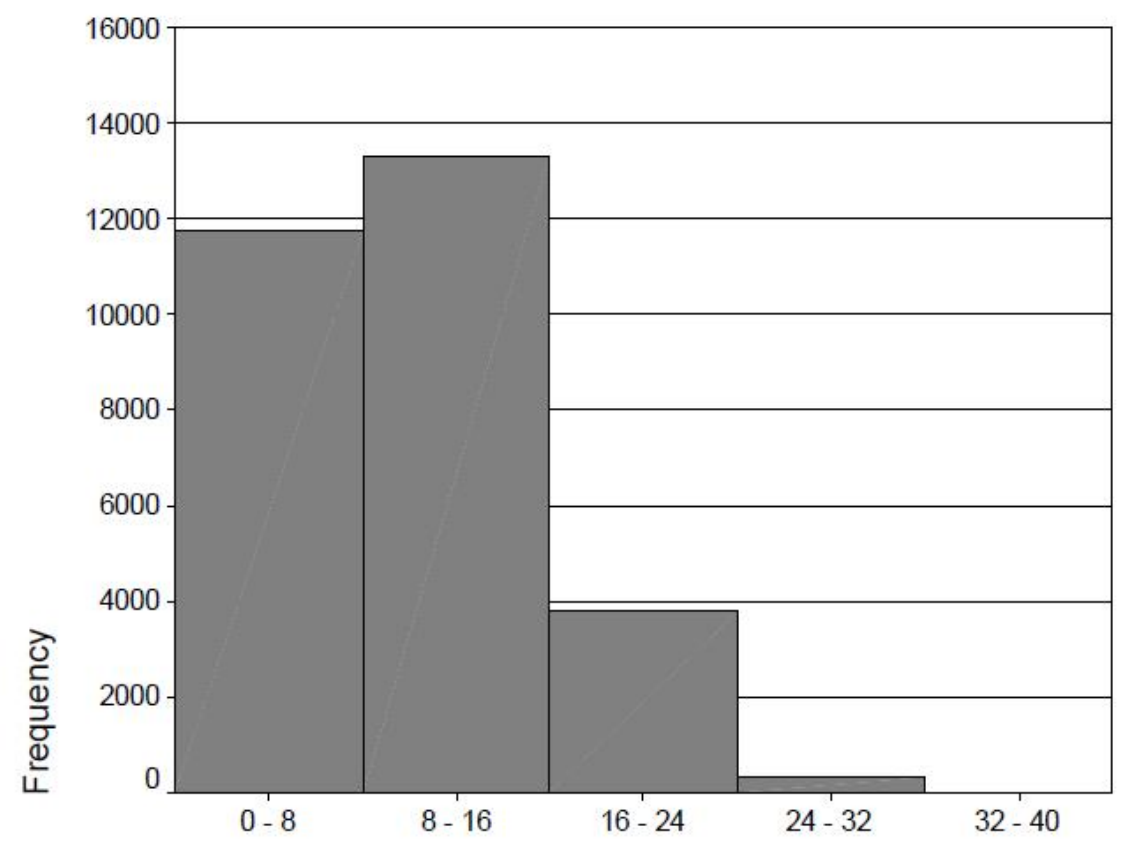

Fig.1. the wind speed histogram in Kish Island station 


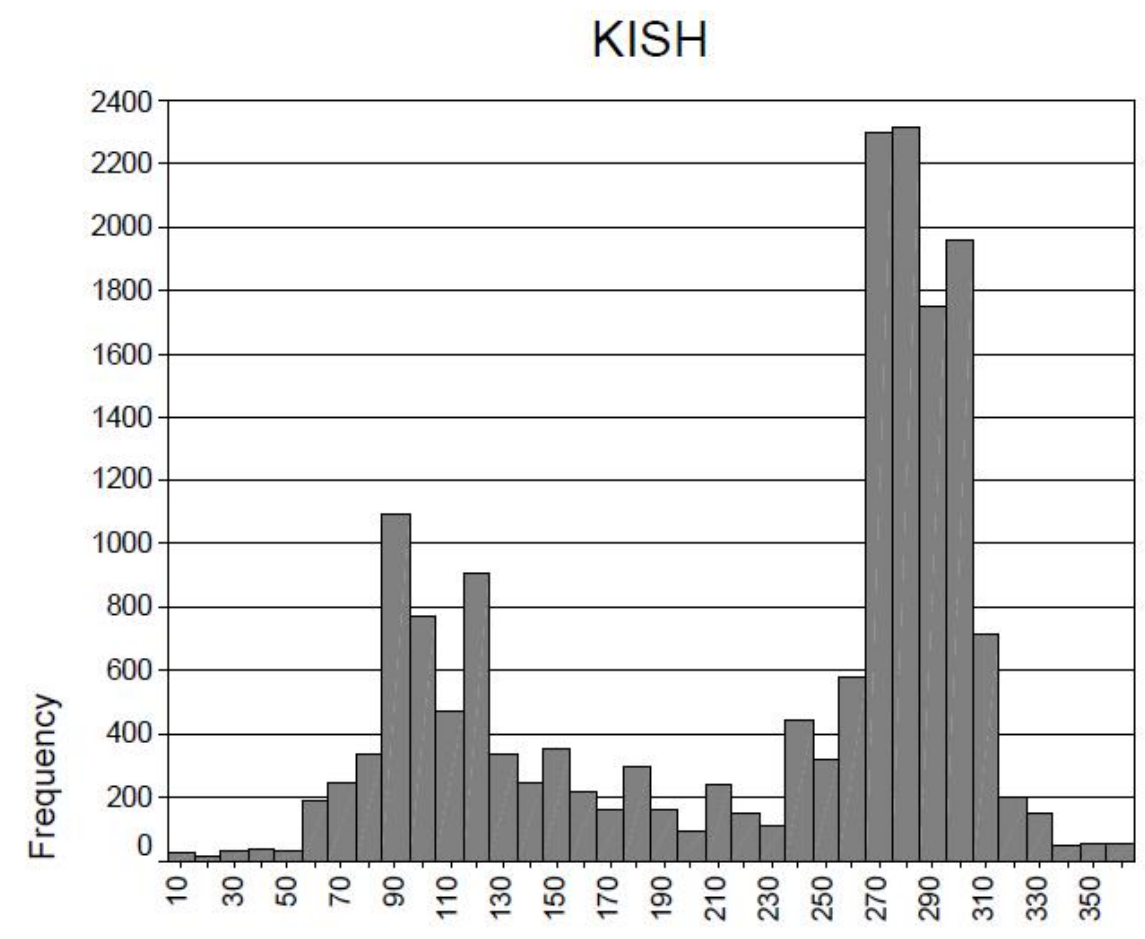

Fig.2. wind speed direction histogram in Kish Island station

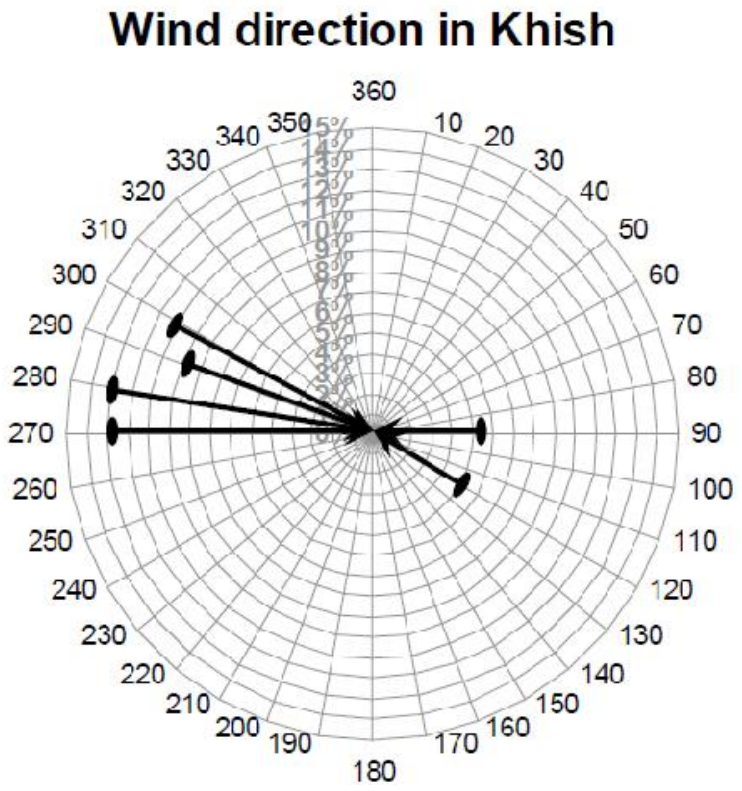

Fig.3. wind blowing main directions in Kish Island

Wind turbine application in the high structures in the Persian Gulf beaches Bahrain global commerce center 
The first use of wind energy as the pure energy occurred in the Bahrain commerce building in 2008. This structure that is designed by the view of ecological signification includes two towers that are connected by three parallel turbines, figure 4, Mostafaie in 2015. In this tower three connecting bridges are holding 225 kilowatts wind turbines with that totally have 675 kilo watts capacity, each of these turbines has 29 meters in diameter and they are toward the north of Persian gulf, figure5, this building that is similar to sail is capable of producing 11 to 15 percent of whole consuming electricity that is about 1.1 to 3.1 Giga watt annually. This amount is equal to providing light of 300 houses, three designed turbines were started for the first time in April 2008 and they are working 50\% of daily time. http://www.khoobine.com)

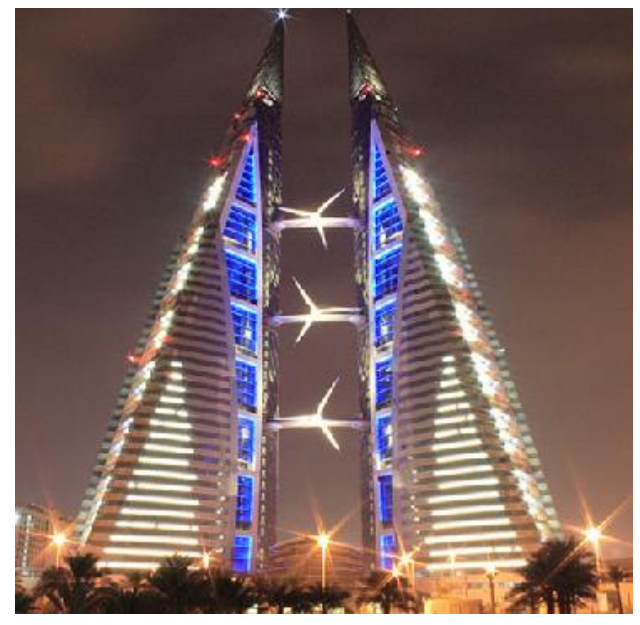

Fig.4. global commerce center in Manama, Bahrain BiceBahrain, n.d

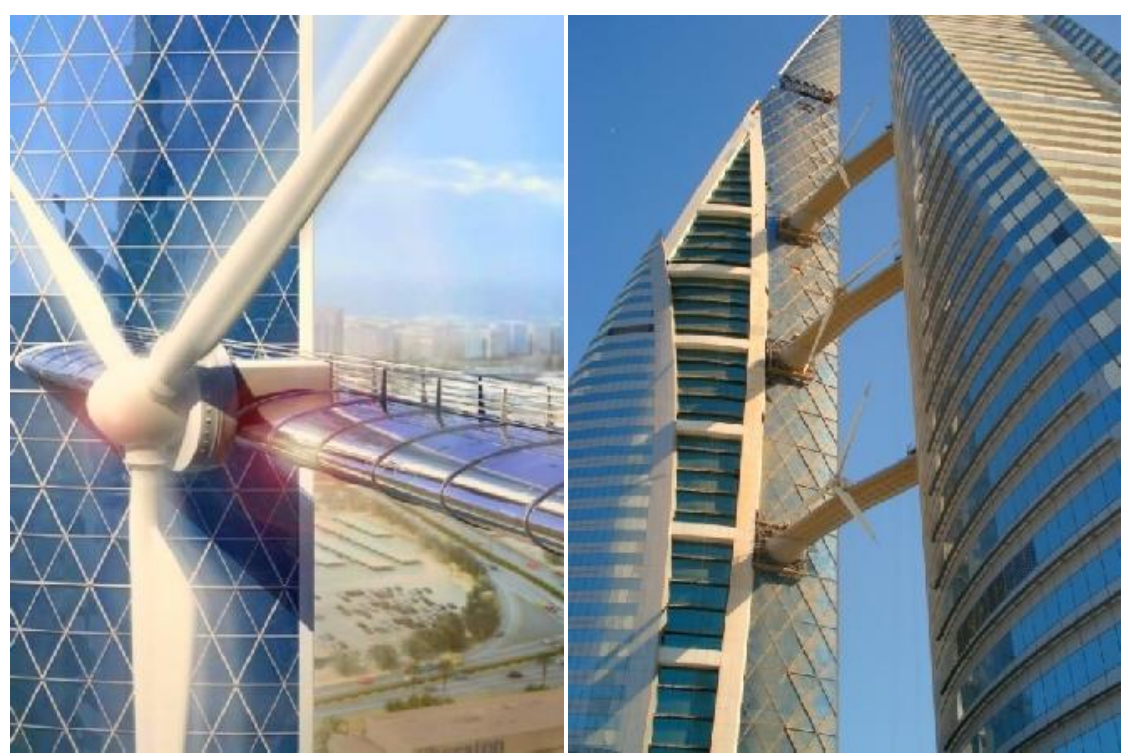

Fig.5. the view of three wind turbines location between two towers

\section{Dubai dynamic towers}

The dynamic tower, the turning tower or running tower also it is known as the architectural running structure or Davinchi tower, it is the tower that is rotating and constructed in Dubai, 
united Arabic of emirate. This structure has 420 meter height. And it is designed in 80 floors, every floor has the capability to rotate 360 degrees separately around it center in every time and the rotating speed could come up to 6 meters in every minute.

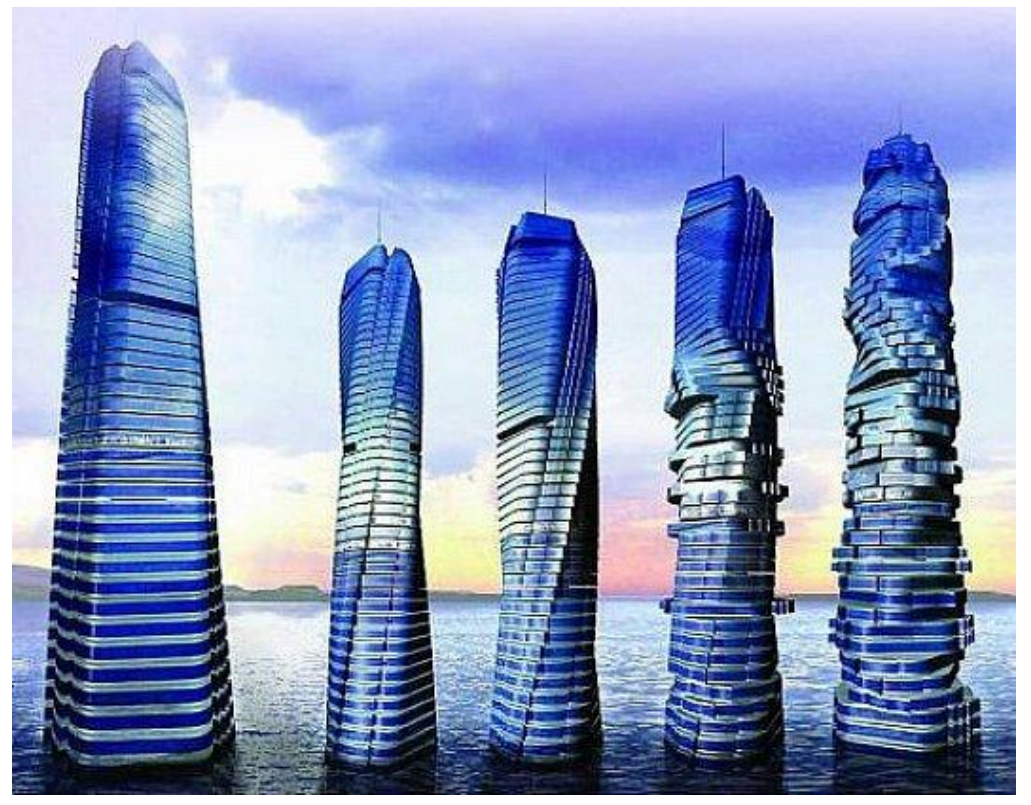

Fig.6. different position of tower floors in rotation

This structure with variable formation is capable to produce its electricity power and wind turbines with the solar panels will produce required energy without any pollution only by using wind and sun shine that has the value more equal to 7 million dollar annually, every turbine can produce 0.3 megawatts electricity, every wind turbine produces about 1 to 1.5 megawatts of electricity and according to the annual 4000 hours /wind energy in Dubai, the applied turbines in the structure could produce 1,200,000 kilo watts energy and by regarding every family average energy consumption at 24000 kilo watts as assessment, every turbine can produce the energy for 50 family, figure 7 and 8 .
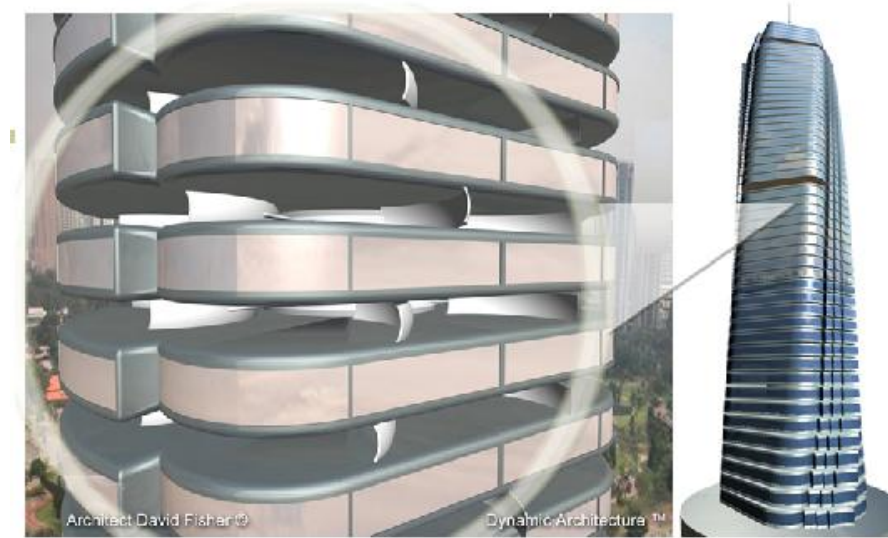

Fig.7. the turbine location between floors 


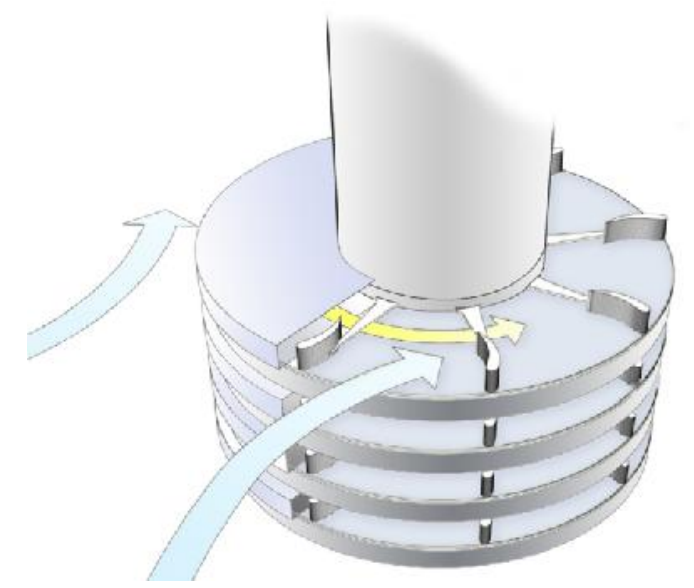

Fig.8. the wind energy application method in turbines

\section{Sun House Tower- Dubai}

The Dubai international finance center will start working in this tower, in this tower 3 wind turbines with 225 kilo watts capacity are installed in the north and 4000 solar panels are installed at the south section, figure 9, 10 that produce the electricity for these two towers.

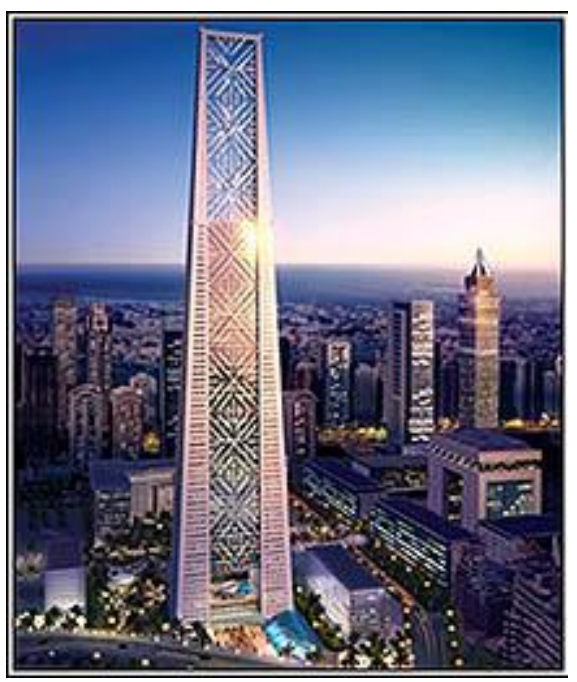

Fig.9. the tower overview 


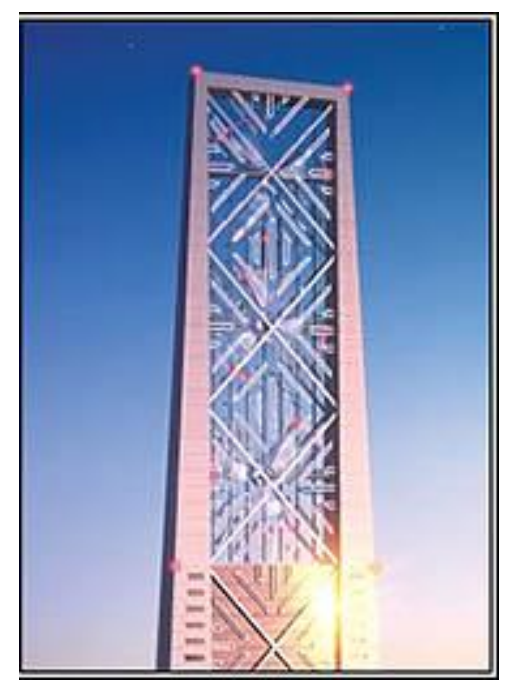

Fig.10. the location of three wind turbine at the top of the tower

\section{Anara Tower in Dubai}

This beautiful tower is constructed in Dubai, this tower designing is done by a British company named Atkins, this sky scraper has 125 floor and between every 27 floors a green space is designed and at the top of the tower, in the central part of its turbine, there is a glass chamber like a capful with perfect view, there is the possibility that the located turbine at the top is for the building energy production, figure11 because the building stature is high, so it is in the wind flows and it can produced the required energy for the building at day and night by changing the wind energy to electricity and if it comes to practice, this building will have the high rate among the intelligent buildings, figure 12 .

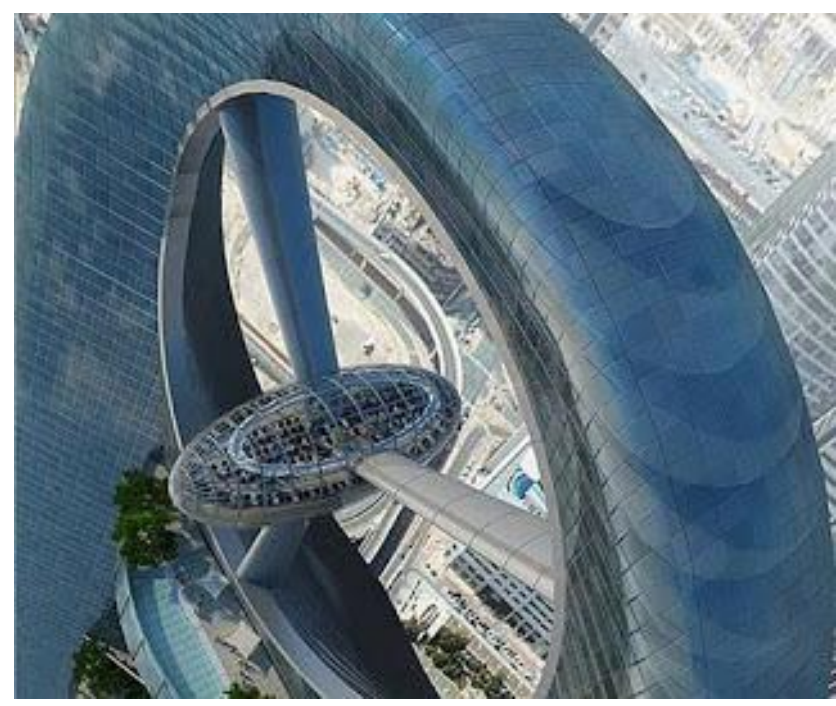

Fig.11. location of turbine at the top of tower and the restaurant in the middle 


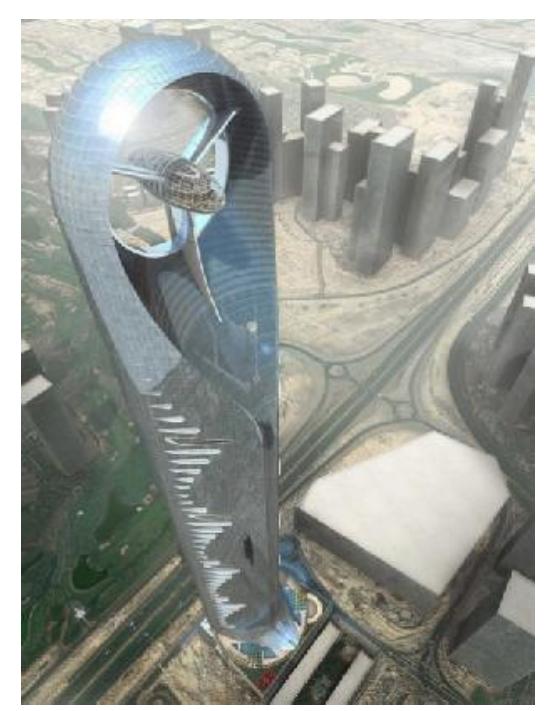

Fig.12. the tower overview

\section{CONCLUSION}

The sky scraper structure construction strategy and development of space in stature as the product of population growth and increase of urbanization and also lack of enough proper land for construction has increased in recent decades and by applicant accumulation in limit level, applying and consuming high degree of energy either during construction or in the time of operation has occurred in these types of buildings, this issue has caused that the wind energy is used greatly and with high speed as the renewable energy in order to produce wind electricity but application of this energy should be regarded in accordant to weather condition in the intended region so that it will provide the macro investment, so in this research by evaluation of aerologic data in Kish island that is located in the Persian gulf and the country beach region, it is realized that this island has the capacity to produce the wind electricity during the whole year in some part of day (midday to night) and also by evaluation $\mathrm{f}$ some samples in sky scrapers in Kish region and according to the available potentials in this region we can proceed to have stable development by the purpose if energy consumption optimization and minimizing the environmental pollution effectively and in vaster view it is possible to increase the quality of civil living environment.

\section{REFERENCES}

[1] Asadpur et al in 2013, the role of climate factors in stable structures designing, Nour city case study, national congress of architecture, urbanization and stable development, Mashhad [2] Hajan, E., 2015, the new method to produce electricity from wind energy, Jam-eJam magazine 
[3] Khalaji A. M. and Safaie B. in 2003, evaluation of wind electricity power plant installed in Iran from the technical and economical view, the $18^{\text {th }}$ international congress of electricity, page 446 .

[4] Danesh P., Saied A. et al in 2009, the environmental psychology knowledge in high sky scrapers by the stable architectural view, the city identity magazine, volme5.

[5] Iran new energy organization informing office, Sana, Iran new energy organization of wind energy, third report.

[6] Dehqhany, M. H. P. M., 2013, the role of environmental factors in stable architectural designing, stable architectural national congress and the civil development, Bukanm page 2 .

[7] Nejad, D. MohammadReza M., the prospect adaptation with the climate, the urbanization architectural magazine, Tehran, 2009, number 24, 72, 483-494

[8] Meysam S., the stable architecture and land, culture and architecture magazine, 2009, page 16

[9] Azizy, M. M., evaluation of space- structural effect on construction in Tehran, fineart magazine Tehran publication, 1998, 4 and 5, page 35

[10] Qhobadian, V., 2003, evaluation of Iranian traditional buildings, Tehran second edition, Tehran publication, page 57

[11] Kaviany, M. R. wind turbines and wind energy potentials evaluation in Iran, geographical research magazine, 1995, volume 36

[12] Gandomkar, A. stable development and environmental saving in Kish island, by the use of wind energy, Persian Gulf magazine

[13] Gandomkar, A., 2006, evaluation of wind energy synaptic in Sistan region, PHD thesis in Esfahan University

[14] Golabchi, M., the criterions to design and construct the sky scrapers, the fine art magazine, Tehran University, 2000, 9, page 9

[15] Mostafaie, M., M. 2015, the role of ecological strategies in structures designing with the view of saving in energy consumption, the collection of articles in the third national architecture and new structures in civil engineering congress, shiraz

[16] Howington, B. S., "Dynamic Thermal Line Rating Summary and Status of the State-ofthe-Art Technology" IEEE TransOn Power Delivery, Vol. 2, No. 3, pp. 851-858, 1987.

[17] Badran, O. (2003), Wind turbine utilization for water pumping in Jordan, Journal of wind, Engineering and Industrial Aerodynamics, 2003, 1203-1214

[18] http://www.khoobine.com 
[19] http://www.slideshare.net/swapnika15/dynamic-da-vincirotating-tower

[20]http://hi4tech.blogfa.com/post-14.aspx

[21] http://memari85.blogspot.nl/2009/02/blog-post_729.html

\section{How to cite this article:}

Fard MHR, Khastu S, Asadpur F. Using wind turbines in sky scrapers to develop thestable architecture (case study: kish island). J. Fundam. Appl. Sci., 2016, 8(2S), 988-1002. 